
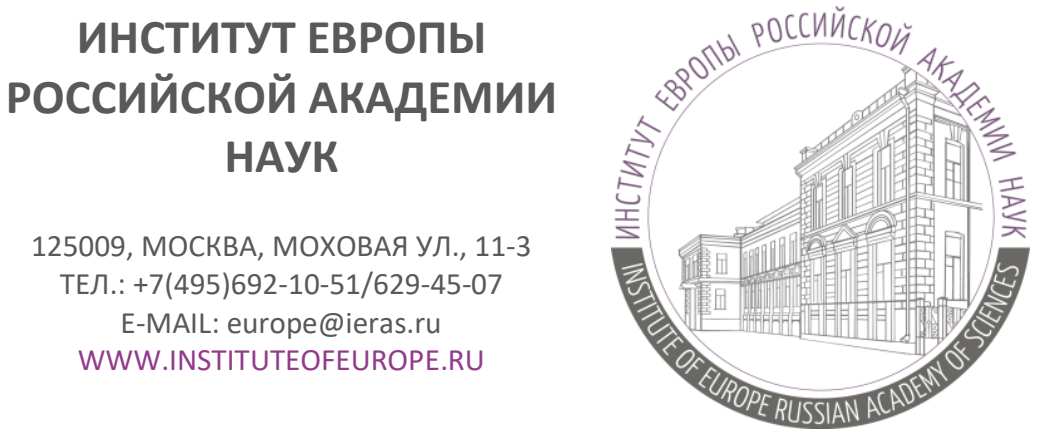

Аналитическая записка №27, 2020 (№210) ${ }^{1}$

\title{
Крупнейшая в послевоенной истории конъюнктурная программа правительства ФРГ
}

\section{Владислав Борисович Белов}

кандидат экономических наук, ведущий научный сотрудник, заместитель директора по научной работе, заведующий Отделом страновых исследований, руководитель Центра германских исследований Института Европы РАН

\begin{abstract}
Аннотация. В начале июня 2020 года Коалиционный комитет правительства Германии одобрил крупнейшую в послевоенной истории программу мер конъюнктурной помощи экономике общим объёмом в 130 млрд евро. Её иель - не только вывести страну из экономического кризиса, обусловленного пандемией коронавируса, но и одновременно увеличить инвестиции в циирровую и энергетическую трансформацию - основу «двойного перехода» ЕС и ФРГ к «экономике будущего». Автор анализирует содержание пакета, эффективность предложенных мер, последствия для партийно-политических процессов и перспективу выхода немеикого народного хозяйства из кризиса.
\end{abstract}

Ключевые слова: Германия, ФРГ, Евросоюз, меры по поддержке конъюнктуры, пандемия коронавируса, ХДС/ХСС, СДПГ.

3 июня 2020 года после непрерывного обсуждения в течение 21 часа Коалиционный комитет ${ }^{2}$ согласовал пакет мер, призванный мотивировать экономических субъектов и

\footnotetext{
${ }^{1}$ DOI: http://doi.org/10.15211/analytics272020

2 Коалиционный комитет (Koalitionsausschuss) - орган правящей коалиции, в который входят представители Кабинета министров и лидеры партий, сформировавших федеральное правительство. Основная задача - координировать сотрудничество между партнерами по коалиции в правительстве, бундестаге и, по возможности, в бундесрате.
} 
домашние хозяйства к активизации спроса и предложения, почти замороженных с середины марта ограничительными мерами государства в условиях пандемии коронавируса. Предыдущая программа помощи правительства объёмом в 600 млрд евро, принятая в конце марта, de facto была направлена на выживание и сохранение максимального количества компаний и рабочих мест в условиях резко сократившейся ликвидности и неопределённости выхода из кризиса ${ }^{3}$. Решение членов Коалиционного комитета правительства ФРГ, направленное на ускорение временно приостановленного германского народнохозяйственного мотора, последовало менее чем через неделю после опубликования Комиссией ЕС плана восстановления экономики Евросоюза объёмом в 750 млрд евро и предшествовавшего ему аналогичного предложения Парижа и Берлина. Очевидно, их основные положения были учтены.

\section{Меры правительственного пакета}

Правительственный пакет, названный «Бороться с последствиями коронавируса, обеспечить процветание, укрепить будущую жизнеспособность» ${ }^{4}$, содержит 57 пунктов с описанием конкретных мер, которые должны обеспечить выход из кризиса и переход к экономическому росту. Общий объём финансирования определён в 130 млрд. Основной срок действия - вторая половина 2020 г. - 2022 г. Согласованные меры предстоит конкретизировать сотрудникам соответствующих структур федерального правительства, которые должны подготовить окончательные тексты законопроектов для их последующего утверждения в бундестаге и бундесрате.

Пакет состоит из трёх блоков:

- меры по ускорению конъюнктурного развития и преодолению кризиса (пп. 1$31)$;

- $\quad$ инвестиции в технологии будущего, в т.ч. в сфере защиты климата (пп. 32-55);

- поддержка мер в рамках ЕС и международной ответственности ФРГ (пп. 56-57).

В первом блоке наиболее важным является уменьшение по 31 декабря 2020 года основной ставки налога на добавочную стоимость (НДС) - с 19 до 16\% и пониженной с 7 до 5\%. Размер сокращения бюджетных поступлений от снижения НДС оценивается в 20 млрд евро.

Вводится ограничение на долю социальных страховых взносов в брутто-зарплате 5 - до 2021 года определена планка в 40\%. Выпадающие доходы, которые в 2020 году оцениваются в 5,6 млрд евро, покрывает государство. Сумма возмещения в 2021 году

\footnotetext{
3 См.: Белов В.Б. Последствия пандемии коронавируса для экономики Германии // Научноаналитический вестник ИЕ РАН. № $2,2020.2-$ C. $83-90$ DOI: DOI: http://dx.doi.org/10.15211/vestnikieran220208390

${ }^{4}$ Corona-Folgen bekämpfen, Wohlstand sichern, Zukunftsfähigkeit stärken. Ergebnis Koalitionsausschuss 3. Juni 2020. - 15 S. URL:

https://www.bundesfinanzministerium.de/Content/DE/Standardartikel/Themen/Schlaglichter/Konjunkturpaket/2 020-06-03-eckpunktepapier.pdf?__blob=publicationFile\&v=9 (дата обращения: 4.06.2020)

5 Эти взносы делятся поровну между работодателями и наёмными сотрудниками.
} 
остаётся пока открытой. Выгоду, в первую очередь, получат работодатели, социальные платежи которых в условиях пандемии существенно выросли.

В целях стабилизации цен на электроэнергию (в ФРГ одни из самых высоких в ЕС) предусмотренная Законом о возобновляемой энергии (EEG) тарифная надбавка в 2021 году составит 6,5 евроцента на киловатт/час , а в 2022 году - 6 центов (в 2020 году 6,76 цента), что позволит потребителям сэкономить 11 млрд евро.

С июня по август будет предоставлена помощь малым и средним предприятиям (МСП), оборот которых в апреле-мае снизился на $60 \%$ и более по отношению к аналогичному периоду прошлого года ${ }^{6}$. Эта программа объёмом в 25 млрд евро имеет внеотраслевой характер. Приоритет - сфера услуг, наиболее пострадавшая от пандемии (туристический, выставочный, гостиничный, ресторанный, спортивный, развлекательный бизнес). Речь идёт о возмещении постоянных издержек в размере от 50 до 80\%, но не более 150 тыс. евро в месяц. Выплаты должны быть осуществлены до 30 ноября. МСП до конца года получат единоразовые выплаты на каждого сотрудника, принятого на практику/обучение - 2-3 тыс. евро после прохождения испытательного срока.

В рамках поддержки федеральных земель и муниципальных (коммунальных) образований государство дополнительно выделяет 4 млрд евро в год на программы поддержки граждан, нуждающихся в жилье; в рамках «Пакта солидарности с коммунами 2020» - 5,9 млрд евро на компенсацию выпадающих бюджетных поступлений (промысловый налог); в сфере общественного транспорта - 2,5 млрд евро в 2020 г. на возмещение снижения доходов от продажи билетов.

Семьи, имеющие право на получение пособий на детей, осенью единоразово получат 300 евро на ребёнка (общий объём помощи - 4,3 млрд евро). Для одиноких родителей, воспитывающих детей, в два раза увеличен необлагаемый доход (до 2022 года).

Среди других мер первого блока, призванных ускорить конъюнктурное развитие экономики, отметим введение ускоренной амортизации на движимое имущество, льгот по налогу на прибыль компаний, приоритетное внимание уже заявленным инвестиционным проектам в сферах государственного управления, безопасности и военно-промышленного комплекса, содействие дебюрократизации ЕС (планирование, государственные закупки, конкуренция) в рамках председательства ФРГ в Совете ЕС, поддержку некоммерческих организаций (через льготные кредиты государственного инфраструктурного банка KfW), а также оказание прямой финансовой помощи детским садам, яслям, школам с продлённым днём, учреждениям культуры и спорта.

Меры второго блока направлены на укрепление средне- и долгосрочных позиций Германии в сфере цифровой и экологической трансформации - так называемого «двойного перехода», предусмотренного в Европейской зелёной сделке и новой

\footnotetext{
${ }^{6}$ Для МСП, созданных после апреля 2019 г., определён период с ноября по декабрь 2019 г.
} 
промышленной стратегии $\mathrm{EC}^{7}$. Для них предусмотрено финансирование объёмом более 50 млрд евро.

Один из приоритетов - сфера НИОКР. Для предприятий предусмотрено налоговое стимулирование исследований до 4 млн евро в год (с 1 января 2020 г. до 31 декабря 2025 г. - 1 млрд евро). Одновременно уменьшается обязательное софинансирование бизнесом практико-ориентированных НИОКР внеуниверситетских исследовательских организаций. Для поддержки наиболее перспективных проектов создаётся фонд объёмом в 1 млрд евро. Особое внимание уделяется сфере энергетики, в т.ч. её цифровизации и межсекторному взаимодействию.

Другое приоритетное направление - сфера мобильности, в первую очередь, автопром и содействие его переходу на выпуск электромобилей в контексте выполнения программ по защите климата ЕС и ФРГ. Налог на транспортные средства в большей степени будет привязан к содержанию выбросов $\mathrm{CO}_{2}$ на километр. Период освобождения от этого налога владельцев электрокаров продлевается с 31 декабря 2025 года до 31 декабря 2030 года. Выплачиваемая при их покупке до 31 декабря 2021 года т.н. «инновационная премия» удваивается - с 3 до 6 тыс. евро (для машин, стоимостью до 40 тыс. евро). Дополнительные льготы вводятся при покупке электромобилей для служебных целей. Объём поддержки - 2,2 млрд евро. Одновременно государство мотивирует МСП, а также организации социальных служб, к замене парка автомобилей с двигателями внутреннего сгорания на машины с электродвигателями. 2,5 млрд евро направляются на расширение сети зарядных станций и стимулирование НИОКР в сфере электромобильности и производства аккумуляторов. Дополнительно для компаний автомобилестроения и производителей комплектующих предусмотрена поддержка прорывных инноваций и стимулирование инвестиций в новые технологии и оборудование в 2020-2021 гг. (всего - 2 млрд евро).

Прорывными можно считать пп. 36 и 37, где идёт речь о пока не принятой «Национальной водородной стратегии» (правительство планировало разработать и принять её в конце 2019 г.). Основная цель - сделать Германию ведущим экспортёром самой современной работающей на водороде техники в мире. Речь идёт как о различном оборудовании, так и о производстве водорода, прежде всего за счёт «зелёных» технологий (без использования природного газа). Предполагая, что собственные мощности не будут покрывать потребность в водороде, Германия рассчитывает на его импорт из других стран. Для этого нужна инфраструктура поставки и хранения, а также наличие необходимых технологий и производств. ФРГ готова предоставить заинтересованным государствам соответствующую поддержку в этом направлении. Также предполагается создать Европейское водородное общество по содействию и созданию совместных международных производственных и инфраструктурных мощностей.

\footnotetext{
${ }^{7}$ Более подробно см.: Белов В.Б. Новая промышленная стратегия Евросоюза // Аналитическая записка №13, 2020 (№196) - 7 c. 07.04.2020 URL:

http://www.instituteofeurope.ru/images/uploads/analitika/2020/an196.pdf (дата обращения: 14.06.2020)
} 
Особое внимание уделено вопросам дигитализации государственных структур (федерации и земель), коммунальных органов власти, кибербезопасности, необходимой технической инфраструктуры (интернет и мобильная связь) и платформ, цифровой трансформации МСП, а также будущим законам, регулирующим сферы электронной регистрации граждан и онлайна. Инвестиции государства в искусственный интеллект будут увеличены к 2025 году с 3 до 5 млрд. Для развития квантовых технологий в цифровой сфере выделяется 2 млрд евро, в т.ч. для разработки и создания минимум двух квантовых компьютеров.

Кроме того, в рамках этого блока предусмотрены: поддержка комплексной модернизации Немецких железных дорог; внедрение городских электробусов и увеличение числа тяжёлых грузовиков с двигателями стандарта Евро-6 в 2020-2021 гг.; расширение возобновляемых источников энергии и проведение энергоэффективной (в контексте выбросов парниковых газов) санации зданий. С учётом уроков пандемии государство уделит особое внимание системе государственного здравоохранения, обеспеченности лечебных учреждений всем необходимым, производству наиболее важных лекарств и медицинских изделий.

Третий блок состоит только из двух пунктов, в которых говорится о важности поддержки Германией программ ЕС по преодолению последствий пандемии и выделении дополнительных средств из госбюджета на борьбу с коронавирусом и расширение гуманитарной помощи в других частях мира, в т.ч. в Африке.

\section{Оценка экономической эффективности пакета}

Снижение ставки НДС занимает одно из основных мест в разработанной Коалиционным комитетом правительственной программе - ему отводится ключевая роль в стимулировании внутреннего потребительского спроса на товары и услуги. Этот инструмент, включение которого в конъюнктурный пакет явилось неожиданным для немецкого экспертного сообщества, способен оказать положительное влияние на рост продаж. В новейшей истории он уже неоднократно использовался в других странах, например, в Великобритании - с 17,5 до 15\% в период с 1 декабря 2008 года по 31 декабря 2009 года.

На наш взгляд, позитивный эффект от снижения НДС частично будет сглажен за счёт запланированного ритэйлерами существенного снижения цен, призванного уменьшить накопленные за период локдауна товарные запасы. Основную выгоду потребители получат при покупке дорогих товаров (автомобилей, мебели, оборудования для кухонь и т.д.), цены на которые могут вновь вырасти в 2021 году. Даже если торговцы не сбавят цены, зафиксированные в прайс-листах на 1 июля 2020 года, покупатели имеют возможность обсудить с ними их право на «неуплату сниженного на $3 \%$ НДС». Экономию можно также получить при заказе услуг ремесленников - весьма недешёвых в Германии различного рода ремонтных и строительных работ.

Понятно, что обусловленный государством всплеск потребления во второй половине 2020 года, особенно дорогостоящих товаров длительного пользования, может оказать 
негативное влияние на объёмы продаж в начале 2021 года. Но государство рассчитывает, что оно будет компенсировано увеличением покупок по другим товарным группам, а также ростом активности во всех секторах сферы услуг.

Отметим очевидные позитивные конъюнктурные эффекты, связанные с содействием спросу со стороны федерации, земель и коммун и различных хозяйствующих субъектов, получающих от них помощь. Положительное воздействие окажут также различные выплаты и льготы семьям с детьми.

Наряду со стимулированием конъюнктуры Коалиционный комитет особое внимание уделил инвестициям в прорывные технологии и инновации. По своему содержанию предложенные в этой части пакета меры направлены на поддержку энергетической и цифровой трансформации немецкой экономики и коррелируют с основными положениями Европейской зелёной сделки и новой промышленной стратегии ЕС. Наряду с этим они могут привести к определённому положительному конъюнктурному эффекту. В первую очередь это относится к комплексному стимулированию государством спроса на электромобили, особенно повышенной «инновационной премии», которая, как и снижение НДС, призвана мотивировать экономических агентов к их приобретению в последующие полтора года ${ }^{8}$. Наверняка, возрастут закупки в рамках различных НИОКР.

Естественно, государство рассчитывает, что прежде всего будет расти потребление товаров и услуг отечественных производителей. Но, как будет формироваться итоговая корзина потребления в 2020-2021 гг. и какова будет её «национальная составляющая», можно будет судить по данным статистики, которая появится только в первом квартале 2022 года.

\section{Последствия для партийно-политической жизни ФРГ}

Конструктивная работа Коалиционного комитета и предложенный им весьма содержательный пакет мер свидетельствуют о сохранении достигнутого в февралемарте консенсуса в правительственной коалиции. С высокой долей вероятности в ближайшее время пакет будет одобрен бундестагом и бундесратом.

Несмотря на «равноправное участие и одинаковый вклад» коалиционных партнёров в подготовку конъюнктурной программы в выигрыше оказался блок ХДС/ХСС. Попытки новых председателей СДПГ С. Эскен и Н. Вальтер-Борянса укрепить свой имидж как руководителей и доказать высокий уровень своей компетентности успехом не увенчались. Так, например, они отнесли к своим заслугам решение отказать лоббистам немецкого автопрома в поддержке продаж легковых машин с бензиновыми и дизельными двигателями. Однако, за это были подвергнуты жёсткой критике профсоюзами, посчитавшими, что руководство социал-демократов «предало интересы» наёмных работников. Неудачей закончились попытки вице-канцлера, министра финансов О. Шольца включить в пакет пункт о списании «старых» долгов коммун.

\footnotetext{
${ }^{8}$ Ожидается, что производители электрокаров также предоставят дополнительные скидки.
} 
Опросы, проведённые через неделю после презентации пакета, не изменили предшествующий показатель популярности ХДС/ХСС. Если бы выборы в бундестаг состоялись 14 июня, то за блок проголосовали бы $40 \%$ избирателей. А вот популярность социал-демократов упала - с 16 до 14\%. Эти 2\% получила партия «Союз 90/Зелёные» - основной кандидат на вхождение в будущую коалицию с ХДС/ХСС в 2021 году. ${ }^{9}$

После презентации франко-германского плана восстановления экономики ЕС и предложенного не менее амбициозного национального плана федеральный канцлер А. Меркель ещё больше укрепила свои позиции неформального лидера партийного союза. Это явный плюс в борьбе за места в бундестаге, которая начнётся в 2021 году, а также на фоне предстоящего председательства Германии в Совете ЕС. В его рамках основной задачей станет преодоление последствий пандемии в Евросоюзе и обеспечение экологической и цифровой трансформации экономики стран-членов.

\section{Выводы}

Разработанные Коалиционным комитетом федерального правительства комплексные меры вполне могут содействовать одновременному решению двух основных задач. С одной стороны, остановить падение производства товаров и услуг и постепенно перейти к экономическому росту. С другой, содействовать «двойному переходу» экономики за счёт «инвестиций в будущее» в приоритетные сферы и отрасли народного хозяйства.

Одним из основных конъюнктурных инструментов государство выбрало снижение НДС, что удивило экспертное сообщество. Также неожиданным стал отказ лоббистам из автопрома поддержать сбыт и производство автомобилей с двигателями внутреннего сгорания.

Германия готова инвестировать в масштабное производство и использование водорода как одного из основных видов альтернативного сырья и топлива будущего, а также в необходимое для этого международное сотрудничество с другими странами. У России в этом отношении есть хорошие шансы занять свою нишу.

Принятие конъюнктурного пакета укрепило позиции союза ХДС/XСС и его неформального лидера А. Меркель, что подтверждает сделанный нами ранее прогноз о победе этого блока на выборах в бундестаг в 2021 году и последующем заключении коалиции с «зелёными» ${ }^{10}$. Запланированные государством меры конъюнктурной поддержки экономики способны существенно смягчить негативное влияние пандемии и создать предпосылки для постепенного перехода к росту ВВП уже осенью 2020 года. По-прежнему многое зависит от возможной второй волны COVID-19 - её силы и

\footnotetext{
${ }^{9}$ Результаты опроса исследовательской группы Forsa. См.: Sonntagsfrage Bundestagswahl. 13.06.2020 URL: https://www.wahlrecht.de/umfragen/ (дата обращения: 13.06.2020)

${ }_{10}$ Белов В.Б. ФРГ: партийно-политическая жизнь в условиях пандемии // Аналитическая записка №21, 2020 (№204). - 6 c. 28.04.2020 URL: http://instituteofeurope.ru/images/uploads/analitika/2020/an204.pdf (дата обращения: 14.06 .2020 )
} 
продолжительности. На сегодняшний день вполне достоверными представляются следующие макроэкономические оценки итогов 2020 года: падение ВВП на 6-8\%, дефицит госбюджета - более 7\%, отношение величины госдолга к ВВП более $75 \%$.

\section{The German government's largest market reviving oriented package in post-war history}

Abstract. In early June, the German government's Coalition Committee approved the largest program of market-oriented assistance to economy in the post-war history, with a total amount of 130 billion euros. Its goal is not only to lead the country out of the economic crisis caused by the coronavirus pandemic, but also to increase investment in digital and energy transformation - the basis of the European green deal. The author analyzes contents of the package, efficiency of the proposed measures, consequences for party-political processes and prospects for the German economy's recovery from the crisis.

Keywords: Germany, European Union, measures to support the conjuncture, coronavirus pandemic, $C D U / C S U, S P D$.

Дата выпуска: 15 июня 2020 года.

Материал доступен для скачивания по адресу: www.instituteofeurope.ru/publications/analytics 